\title{
Reflexión crítica en torno al hecho religioso*
}

\author{
John Alexis Rengifo Carpintero* \\ Carmen Helena Díaz Caicedo***
}

Recibido: 18 de febrero de 2015 - Revisado: 19 de marzo de 2015 -

Aprobado: 10 de abril de 2015

\section{Resumen}

El hecho religioso, como objeto de estudio, es un acontecimiento que ha de ser abordado desde distintos enfoques disciplinarios si se quiere adentrar en su comprensión más amplia. Por ello, este artículo es un bosquejo investigativo de tal hecho bajo el horizonte conceptual de su origen dogmático-teológico, el de su acción socio-cultural y el del marco de referencia reflexivo filosófico, horizontes que dan cuerpo, cada uno y en su orden, a un apartado, desde los cuales se piensa como acontecimiento que cumple una doble finalidad: la de sacar al hombre de su ser precario, su biología carencial; y la de mostrar que este siempre, en todo momento y lugar, se dirige al mismo fin, brindarle la esperanza al hombre de su propia trascendencia. Pero a un terrible costo, la pérdida del juicio crítico. Cada uno de estos horizontes de análisis da cuerpo a un apartado.

Palabras clave: universo de sentido, celebración, símbolo, indescifrabilidad, plenitud de vida.

* Este artículo es el resultado del proyecto de investigación titulado "Indagaciones filosóficas sobre el acontecer religioso", llevado a cabo con el apoyo de la Universidad Santiago de Cali y la mediación social de la Asociación Eslabón Cultural y la Fundación Investigación Creativos. DOI: http://dx.doi.org/10.15332/s0120-8454.2015.0087.07

** Doctor en Educación. Licenciado y magister en Filosofía de la Universidad del Valle. Profesor e investigador de la Universidad Santiago de Cali. Director de la Fundación Investigación Creativos. Director de Investigación crítica de la Asociación Eslabón Cultural. Investigador del grupo de investigación Gicompu. Líneas de investigación: Filosofía crítica, Pedagogía crítica, Antropología cultural e Historia comparativa de las religiones. Dirección postal: Cl. 5 \# 62-00, barrio Pampalinda, Santiago de Cali (Colombia), correo electrónico: jalexrecar@yahoo.es

*** Profesional en Teatro y Danza del Instituto Popular de Cultura. Profesora de la institución educativa Liceo los Alpes. Directora de la Asociación Eslabón Cultural. Investigadora de la Fundación Investigación Creativos. Líneas de investigación: Teatro del oprimido, Antropología teatral y Pedagogía crítica. Dirección postal: Cr. 26 i 1 \# 72-03, barrio Los Lagos I, Santiago de Cali (Colombia), correo electrónico: asoeslaboncultural@gmail.com 


\title{
Critical reflection about the religious fact ${ }^{*}$
}

\author{
John Alexis Rengifo Carpintero* \\ Carmen Helena Díaz Caicedo***
}

A bstract

The religious fact, as an object of study, is an event that must be approached from different disciplinary approaches if you want to delve into its broader understanding. Therefore, this article is a research outline of such fact under the conceptual horizon of its dogmatic-theological origin, its socio-cultural action and reflective philosophical frame of reference, horizons that embody, each one and in their order, to a section, from which it is thought as an event that serves a dual purpose: to take man out of his precarious being, his deficiency biology; and to show that this always, in every time and place, is directed to the same purpose, to give hope to man of his own transcendence. But at a terrible cost, the loss of critical judgment. Each of these horizons of analysis embodies a section.

Keywords: Universe of sense, celebration, symbol, indecipherability, fullness of life.

This article is the result of the research project entitled "Philosophical Inquiries about religious events", carried out with the support of the Santiago de Cali University and the social mediation of the Cultural and Creative Link Association Research Foundation.

** Doctor of Education. BA and MA in Philosophy from the Universidad del Valle. Professor and researcher at the Universidad Santiago de Cali. Creative Director of the Research Foundation. Critical research director of Cultural Association Link. Investigator of the research group Gicompu. Research areas: Critical Philosophy, Critical Pedagogy, cultural anthropology and comparative history of religions. Address: Cl 5 \# 62-00, Pampalinda, Cali (Colombia), e-mail: jalexrecar@yahoo.es

*** Professional Theatre and Dance Institute of Popular Culture. Professor of the school Liceo Alps. Director of the Cultural Association Link. Researcher Creative Research Foundation. Research areas: Theatre of the Oppressed, theatrical anthropology and Critical Pedagogy. Address: Cr 26 i 1 \# 72-03 barrio Los Lagos I, Cali (Colombia), e-mail: asoeslaboncultural@gmail.com 


\title{
Réflexion critique autour du fait religieux*
}

\author{
John Alexis Rengifo Carpintero** \\ Carmen Helena Díaz Caicedo***
}

\section{Résumé}

Le fait religieux, comme objet d'étude, est un événement qui doit être abordé sous différents angles disciplinaires si l'on veut approfondir sa compréhension. $C^{\prime}$ est pour cette raison, que cet article est une ébauche d'investigation de ce fait, réalisé sous la perspective conceptuelle de son origine dogmatico-théologique, celle de son action socio-culturelle et du cadre de référence reflexivo-philosophique, perspectives qui ont donné forme, chacune dans son ordre, a un paragraphe à part, à partir desquels il est admis comme un événement qui a une double fonction : celle de sortir l'homme de sa situation précaire, de sa biologie carentielle; et celle de montrer que celui-ci, en tout lieu et en tout moment, se dirige vers le même but, donner l'espoir à l'homme de sa propre transcendance. Mais tout cela à un coût très élevé, la perte du jugement critique. Chacun de ses perspectives d'analyse donne place à un paragraphe à part.

Mots clés: Univers de sens, célébration, symbole, indéchiffrable, plénitude de vie.

* Cet article est le résultat du projet de recherche intitulé «recherches philosophiques sur les événements religieux», réalisée avec le soutien de l'Université de Santiago de Cali et de la médiation sociale de la Fondation de recherche Creative Association lien culturel et naturel.

** Docteur de l'éducation. BA et MA en philosophie de l'Université del Valle. Professeur et chercheur à l'Université de Santiago de Cali. Directeur de la création de la Fondation de la recherche. Directeur de recherche critique de l'Association culturelle Link. Chercheur du groupe de recherche Gicompu. Les domaines de recherche: la philosophie critique, la pédagogie critique, anthropologie culturelle et d'histoire comparée des religions. Adresse: Cl. 5 \# 62-00, Pampalinda, Cali (Colombie), email: jalexrecar@yahoo.es

*** Théâtre professionnel et la danse Institut de la culture populaire. Professeur de l'école Alpes Liceo. Directeur de l'Association culturelle Link. Fondation de la recherche créative de chercheur. Domaines de recherche: Théâtre de I'Opprimé, I'anthropologie théâtrale et pédagogie critique. Adresse: $\mathrm{Cr} 26$ i 1 \# $72-03$ barrio de Los Lagos I, Cali (Colombie), e-mail: asoeslaboncultural@gmail.com 


\section{Introducción}

A partir del mes de septiembre del 2010, el grupo de investigación creativos de la Asociación Eslabón Cultural se dio a la tarea de estudiar el hecho religioso, en un primer momento como una tarea de aula nacida del curso Historia comparativa de las religiones, dictado en la Fundación Universitaria Católica Lumen Gentium; pero, en un segundo momento, cobró una relevancia académico-investigativa para quienes de una u otra manera nos veíamos agobiados por intentar escudriñar en eso que hace que mi creencia sea mi creencia y no otra creencia. Es decir, en eso que hace que al interior de una comunidad se cree un universo simbólico llamado religión que le confiere sentido, no solo a la vida de los fieles, sino que a través del tiempo y el espacio ha pervivido históricamente en cualquier cultura o mundo de la vida ${ }^{1}$, como una fuerza que genera un tipo de subjetividad específica, unas prácticas discursivas propias a la mentalidad de cada región, entorno o territorio preciso, y unas consideraciones ideológicas, políticas, culturales o cosmovisivas paradójicamente semejantes, en lugar de ser únicas. A tal punto podemos hablar de religiones geográficas: por ejemplo, el judaísmo construyó la idea de un Dios sin imagen ni nombre porque era un pueblo sin tierra, sin amor por lo natural, de ahí su tendencia a un pensamiento siempre teóricouniversal; por el contrario los dioses del pueblo griego nacen del amor de los helenos por la tierra (polis), el mar y la naturaleza, por lo que el mundo, y con ello los dioses, tenían sentido si se les podía representar a través del arte de las musas o del escultor. Mientras que en las comunidades indígenas de América del Sur, es el animismo natural el que gobierna la constitución imaginaria del pueblo. En estos pueblos rodeados de valles, llanuras, montañas, flora y fauna, los dioses se manifiestan en los elementos naturales, por ello la reverencia a la tierra, a la luna, al sol y a las plantas; la naturaleza deviene unida (intrincada), en una acción de co-dependencia del todo con las partes y de las partes con el todo.

Así, el hecho religioso como fenómeno social, cultual y colectivo (consideración conceptual tomada en préstamo de la obra del autor Emile Durkheim titulada Las formas elementales de la vida religiosa) se nos presenta en toda su dimensión y complejidad como un elemento social a ser no solo estudiado académicamente, sino, antes bien, a ser entendido, comprendido, dilucidado e investigado en todo su acontecer teórico-práctico. Esto es, en tres aspectos o dimensiones: como la compensación artificial por excelencia, de la precariedad biológica del hombre (nivel antropológico-filosófico), con Louis Bolk (1926), Arnold Ghelen (1993) y Odo Marquart (2001); como un hecho social y colectivo (nivel sociológico), con Emili Durkheim (1999) y Max Weber (1999); y finalmente, como la constitución real de un mundo imaginario al que llamamos espíritu o universo de sentido,

1 Entendemos por mundo de la vida un trasfondo cultural socialmente compartido y racionalmente estructurado, que le confiere a los actores sociales la posibilidad de comprenderse comunicativamente sobre algo en el mundo. A su vez, reconocemos que este se presenta de forma paralela a los sistemas de acción cultural, político y económico, pero bajo medios distintos. El mundo de la vida se organiza en plexos de acción que dan cuenta de acciones producidas colectivamente en situaciones particulares, y cuyo principal medio es el acto comunicativo; a diferencia de los sistemas de acción político y económico donde la acción social de organización y convivencia de un colectivo se ejerce a través de los medios poder y dinero respectivamente. Tal consideración epistemológica la tomamos a préstamo de la Teoría de la acción comunicativa de Habermas, en su segundo tomo, aunque con algunas consideraciones críticas. 
que lleva al hombre hacia la trascendencia (nivel teológico-filosófico), desde Nietzsche (2000), a través del cual logramos percibir la diferencia que pervive entre el hecho religioso como fenómeno colectivo y las formas comportamentales tribales de relacionarse con los demás, para escapar a la vaciedad de un mundo de la vida dado, pero al mismo tiempo indescifrado ${ }^{2}$.

En esta empresa partimos de una hipótesis de base: el hecho religioso es un esfuerzo humano para encontrarle sentido a su propia existencia y abandonar la carencia de su ser biológico, en una apuesta existencial por descifrar su propio mundo, a través de la cual logramos evidenciar que es el hecho social y colectivo que más fácilmente podemos medir en términos cuantitativos y cualitativos. Por tal razón nuestro afán epistemológico es realizar un examen exhaustivo del hecho religioso en términos comparativos, ello es, examinando las posibles manifestaciones de este en distintas culturas que nos puedan mostrar si nuestra hipótesis de base es acertada o incurre, por el contrario, en un error conceptual, metodológico o procedimental.

Para tal labor, la filosofía como disciplina de estudio, y la genealogía como herramienta metodológica de investigación, serán los pilares conceptuales que nos permitirán pensar el hecho religioso transdisciplinarmente junto a la sociología y la antropología. Por lo que en nuestro ejercicio de descubrir el acontecer religioso, la acción social, política y ética religiosa, su devenir histórico y su casuística social, la filosofía (desde una antropología-cultural) nos servirá de sustento epistemológico, ya que a través del estudio de casos de comunidades específicas, podemos entender mejor las propiedades conceptuales, dogmáticas y consustanciales del fenómeno religioso, mientras que a través de la genealogía indagaremos por el acontecer religioso como un fenómeno cultural históricamente construido, constituido y legitimado por agentes sociales distintos, plurales y heterogéneos, no solo en pos de otorgarle poder y dominio a una clase social sobre otra, sino antes bien, con el ansia de resolverle el problema existencial de base en el hombre, la indescifrabilidad de su propio mundo de la vida ante su ser carencial.

\section{El hecho religioso: su función real}

¿Cuál es la función social real del hecho religioso?, ¿qué tipo de imaginario instituye en la subjetividad de un creyente?, ¿qué elementos constitutivos pueden hallarse en distintos fenómenos religiosos? Son estas cuestiones algunas de las problemáticas que intentaremos esgrimir en este artículo con el ánimo de ofrecer una pequeña mirada sobre el mismo.

2 La noción de mundo de la vida indescifrado es una consideración epistemológica hecha por el profesor John Alexis Rengifo en este escrito, a través de la cual manifiesta la vaciedad biológica y ontológica con la que el hombre viene al mundo. 
El hecho religioso más que un thelos metafísico es un esfuerzo humano por superar la minusvalía orgánica del hombre (Bolk, 1926). Esto es, el hecho religioso es un acto colectivo en el trasfondo cultural del mundo de la vida que cumple una función más biológico-existencial, que socio-política, sacar al hombre de su ser precario, carencial, de su estado biológico de ser inacabado, para transformarlo en un ser eminentemente espiritual (cultural) (Ghelen, 1993). Por ello, la religión, en tanto hecho, no es un fenómeno que surja del hombre como una acción que llega a él de un transmudo, o submundo o inframundo, en todo caso que venga a él desde un más allá, sino que por el contrario nace de él como la mejor herramienta para superar su estado de ser biológicamente precario.

El hombre viene al mundo como un ser abierto a él, porque desde el momento de su nacimiento su ser carencial se ve sometido a la apertura cognitiva, sensorial y afectiva de estímulos polimorfos, heterogéneos y plurales que representan para este un espectro sin fin de sonidos, olores, formas, sabores y demás, sin que este pueda evitarlo, en términos biológicos; más aún, el mundo se le aparece como algo ajeno ya que este es una construcción constante con el otro, otro que representa la tragedia de su propia existencia, su fatalidad, necesitar del otro, vivir con el otro, pero sin querer estar con él, ya que este se impone como una existencia ajena, extraña, diferente y en muchas ocasiones opuesta a la existencia propia que siempre está en un querer imponer su propia ley, la norma, el mandato, la exigencia procedimental, la opinión pública (Nietzsche, 2000), la apariencia, su propia voluntad, y cuya máxima expresión es la sociedad masificada de consumo burgués y capitalista actual. Por ello, este se oculta en la esperanza de un mundo mejor, de un más allá a través del cual él pueda remediar su propia tragedia, la tragedia de estar y de haber nacido en un mundo de la vida que no pudo pedir no estar, no nacer (Foucault, 1994). Es en este momento cuando la creencia en un más allá cobra valor para su propia vida, la esperanza en una vida cualitativamente mejor se presenta ante él como la renuncia viciosa a asumir la tragedia de su propia existencia. No hay un mundo mejor, el único mundo mejor es el que se pueda construir día tras día con lo que más amas y por lo que más amas; más aún, el problema no es tanto encontrar el camino de la salvación o hacia la vida eterna, el problema real es cómo llegar a él, y es allí donde se le presenta al hombre la tercera causa de la indecifrabilidad del mundo, iquiero ser salvo pero no sé cómo!, peor aún, ¡quiero ser salvo!, pero, ¿qué sistema de creencia o cosmovisión posee la razón para brindarme el camino hacia una vida superior? Tan solo el mundo de la vida propio en el que nació le ofrece la solución, y esto hace que ya, de antemano, su visión del mundo sea una visión amañada de la realidad. Pero cuando este se da cuenta de tal problema existencial, es cuando nuevamente el mundo le aparece, deviene ante sus ojos como un tratar de descubrir lo que hay en él, en pos de saber para qué y por qué está en él. No obstante esto, el hombre vive muy lentamente ese proceso de descubrir el mundo como un horizonte inagotable de posibilidades indescifradas del acontecer mediato de la totalidad del mundo. Por ello, a este tan solo le es dado el mundo en una porción diminuta para ser comprendido; y él, poco a poco tendrá que encontrarle sentido a ese acontecer propio, social y material llamado mundo de la vida, que de antemano es vedado por ser una realidad total que aquel no puede abarcar 
ni cognitiva, ni biológica, ni socialmente. Por lo que el mundo se le escapa, bien como ser biológico carencial, bien como una realidad social en constante construcción con el otro, o bien como una realidad espiritual que desconoce el camino de la trascendencia pero que lucha por llegar a ella.

\section{Aspecto sociológico}

Desde el punto de vista sociológico, el hecho religioso es un sistema ordenado de creencias, prácticas, rituales, dogmas y puede surgir de distintas clases sociales (Max Weber, 1999). En otras palabras, es un fenómeno social y colectivo que articula los distintos actores sociales en torno a la constitución y construcción de un mundo imaginario, dialógicamente articulado y narrativamente discutido.

Además de estos rasgos hay uno fundamental que se presenta de manera similar en diferentes culturas, religiones o cosmovisiones, a saber, la dimensión comunitaria. Y es que todo sistema de tendencia religiosa se manifiesta y se desarrolla en un contexto social, colectivo o político según cada espacio y tiempo. Esto se sustenta en el caso de las prácticas rituales que siempre tienden a incluir la reunión de la comunidad en torno a lo ceremonial; además la necesidad de que la cosmovisión sea compartida implica una participación de toda la comunidad, con lo cual se asegura la pervivencia del sistema de pensamiento y su continuidad en el tiempo, sea por medio de la tradición oral o la sistematización de textos sagrados.

Un ejemplo de ello lo podemos observar en la celebración de la eucaristía vivida como fiesta sacramental al interior del catolicismo, pero que lo hemos podido constatar en distintas tradiciones religiosas de distinta confesión, como son: la tradición animista de la comunidad de los Nasa en el departamento de Cauca en Colombia, la tradición politeísta en el sincretismo propio de la santería de Cuba, Brasil, Colombia etc.

Dentro de distintas tradiciones religiosas a lo largo y ancho de la historia, la eucaristía representaba un ritual de celebración, conexión, fiesta y comunión en torno y derredor de un ente en común: la naturaleza divina del sol. Su genealogía la podemos remontar al culto de Isis y Osiris en Egipto hacia el siglo (VII a. C.), y que posteriormente pasó a Grecia disfrazada a través de los misterios de Eleusis y de Orfeo. Por ello, en este apartado que traemos a modo de ejemplo para mostrar la fuerza social que posee el hecho religioso, examinaremos brevemente, la eucaristía como un ritual ${ }^{3}$ que, a nuestro modo de ver, comporta la estructura de un gesto simbólico significativo. Es decir, mostraremos que para esta tiene la relevancia de una fiesta sacramental (Taborda, 1987), en donde se manifiestan tres cosas: la primera, el sentir del pueblo, sus vivencias y experiencias de fe; la segunda, gestos simbólicos vivenciales y experienciales

3 Cuando hablamos aquí de ritual, lo hacemos desde el punto de vista de la acción positiva y transformadora que este debe poseer en la sociedad. 
para los fieles que cobran lugar en la acción litúrgica empoderada en el gesto significativo eucarístico; y la tercera, un acto de celebración festejo, una acción gestual y simbólica de celebración que saca al creyente del mundo rutinario tecno-científico de tedio, consumo y masificación audio-visual.

Antes de proseguir con el tema es pertinente aclarar en qué consiste el acto ceremonial, la celebración simbólica de la eucaristía.

La eucaristía es una fiesta ceremonial de vida, en donde el fiel conmemora la pasión de Jesús de Nazaret, su muerte y resurrección ${ }^{4}$. Este conmemorar es la representación emocional, evocativa, experiencial por referencia al objeto referencial Jesús, del padecer de Cristo. Pero en este padecer lo que se celebra de forma simbólica y a través de una serie de gestos significativos, es la resurrección de este. Pero se celebra una resurrección anticipada por un acontecimiento significativo sumamente relevante: la celebración de la última cena del cordero.

En el sacramento eucarístico los dos elementos del símbolo se hacen evidentes: el primero, el acto comunicativo lingüístico que conmemora el mensaje de salvación a través de la fuerza persuasiva de una palabra bien dicha, bien transmitida, bien entendida (liturgia de la palabra), esto es mensaje de esperanza, de renovación, de cambio, de trasformación de unión entre todos, cuerpo de Cristo. Por su puesto esta se emite por alguien estatuido legítimamente por el cuerpo eclesial, el sacerdote, y lo que dice lo dice en nombre (símbolo), del poder que le confiere la ecclesia, que a su vez cree en el testimonio contenido en la narración sagrada (libro sagrado, palabra de Dios). El segundo, el gesto simbólico (lenguaje no verbal) de unión del fiel con el cuerpo y la sangre de Cristo (liturgia de la eucaristía), cada uno de los cuales está simbolizado por el pan (ostia, el cuerpo) y el vino (la sangre), que actúan como un vínculo real (simbólico) del fiel con Jesús. Aquí lo importante no está en la realización, por parte del sacerdote, de una acción mecánica de muestra y presentación de los símbolos, sino que, la fuerza ceremonial del gesto simbólico radica en su fuerza experiencial, en la vivencia de fe que el fiel le confiere al acto, y que es plenamente correspondido por el sacerdote; puesto que de no ser así, los fieles saldrían corriendo de la misa. Por ello, el acto de celebración eucarístico es una fiesta o gesto simbólico porque en ella desde el que oficia la celebración, hasta los invitados a la fiesta cada uno está en sintonía con las palabras que se emiten, con los gestos que se realizan y con el canto que celebra.

A través de la celebración ritual de la eucaristía el hombre se hace uno con el creador a través de su unigénito hijo, Jesús. Lo que hace del acto algo ritual a nivel simbólico, ante todo como expresión significativa. Es decir, el fiel lo vive como un hecho de fe. Esto es, el pueblo, la comunidad de creyentes entiende que

4 Celebración que realmente retoma con tintes histórico culturales concretos, aunque desgastados, el mito de Osiris en Egipto, de Eleusis en Grecia, de Mitra en Persia y de Rama en la cultura Aria. Más aún, si forzáramos un poco la historia y nos adentráramos en el Mahabarata, texto épico de la India, cuya antigüedad se remonta al siglo (XIII a. C.) hallaríamos de un modo claro, pero para algunos desconcertante, que los mitos griegos, egipcios y romanos recogen con tintes tenues la sabiduría expresada en tal texto, especialmente en el diálogo entre el dios Krishna y su amigo, discípulo, Árjuna. 
en la fiesta eucarística es Dios el que a través de un gesto simbólico se introduce en sus cuerpos para renovarlos, fortalecerlos y otorgarles esperanza.

La celebración eucarística es eso para el pueblo una celebración, un acto de festejo donde participan de la comunión con Cristo, esto es, se hacen uno con él, pero también entre ellos se hacen uno, el cuerpo de Cristo, por lo que tal festividad se da en un doble nivel: en el de la representación psicológica del símbolo eucarístico, lo que queda en el imaginario colectivo de los fieles; en el de la realización sociológica del acontecimiento celebrado, esto es, en la constitución social de una comunidad de creyentes. Y en este sentido cada fiel reconoce que debe cumplir una serie de funciones como miembro de ese cuerpo. La acción principal, reconocer un acto simbólico: el gesto y las palabras del sacerdote no son solo eso, sino que ambos están revestidos de la fuerza persuasiva de la tradición, pero también de la comprensión significativa que el fiel posee de la palabra, y de quién lo emite. Las acciones secundarias pero no por ello menos importantes: reconocer que cada color, cada olor, cada objeto, cada palabra, cada gesto posee un significado sacramental; es decir, estos no están allí, o se hacen porque si, antes bien todos hacen parte de la fiesta ceremonial de unión con Cristo.

La finalidad de la celebración es el acto más bello en la festividad eucarística. Constituir un universo simbólico y de sentido para el pueblo de Dios, para el fiel, con el objetivo de sacar al hombre de su estado de indigencia espiritual, moral y social para acercarlo a Dios.

El acto eucarístico se convierte en el alimento sagrado, es una puerta abierta al prójimo que desea hacer de su alma refugio de los más necesitados, de los que sufren y requieren consuelo para transformarse en un ser de fuerza y valor. A través del acto eucarístico la conexión cuerpo y alma trasciende desde el referente del Dios supremo, la representación no se limita a un espacio tiempo, pues la dimensión es infinita y eterna, y se convierte en la paz reconfortante, hasta la elevación del propio ser en unión con la divinidad.

Lo más importante de la celebración ceremonial eucarística es la doble acción social, la psicológica y la sociológica. En la acción psicológica, la eucaristía comporta un beneficio existencial para quien asume la importancia del rito ceremonial, del gesto simbólico, el individuo se siente uno con el todo, pero en un proceso de elevación espiritual. En la acción sociológica, la eucaristía actúa como un mecanismo articulador, unificador que se constituye en un horizonte de sentido para el fiel. El hombre ya no está solo en el mundo, el reconoce que a través del acto eucarístico él es uno con Dios y con su cuerpo, o sea, con la comunidad de creyentes. Esta doble acción del gesto simbólico eucarístico actúa en lo real de una manera positiva. Ante el auge de un mundo masificado, tecnocientífico y vacío, la vivencia de fe del dogma eucarístico es una salida, en la doble dirección en la que ya se señaló. Primero, porque le confiere plenitud a la existencia del hombre, a través de la acción trascendente manifestada y vivida en la experiencia de unión con Cristo a través del acto eucarístico del ofrecimiento 
del pan y el vino o cena del Señor. Segundo, porque el hombre partícipe de esta fiesta escapa, sale del vacío existencial y moral al que se ve sometida la sociedad entera por el paradigma de la esfera de valor tecno-científica.

Así pues, la eucaristía es una acción gestual simbólica que se constituye en un horizonte de sentido para el creyente y en un momento de goce espiritual para el fiel, quien se hace uno con él bebiendo su sangre y comiendo su carne, esto es, haciendo parte del misterio de la encarnación espiritual de Cristo. La eucaristía es una celebración que une al creyente con su creador y a estos entre ellos mismos, a través de símbolos significativos cargados de sentido, vividos y experimentados por cada fiel, y por lo tanto le confiere acción significativa a su vida. La vida de estos ya no está vacía, está llena de Cristo cada vez que acepta la fiesta de la celebración eucarística. En esta el hombre se goza de Dios.

De igual modo, el hecho religioso es un acontecer semiológico que se expresa en cada religión del mundo a través de: la acción simbólica de la celebración que nutre, alimenta y es la verdadera vida del culto y del rito que se expresan a través del gesto, la expresión significativa, el símbolo y el signo, desplegado en dos sentidos: en el primero tematizando la comunicación en dos niveles, la verbal y la gestual o no verbal. En el segundo, mostrando que si bien los discursos tienden a ser argumentativos, en su fondo genealógico es la narración la que actúa como sustrato fundamental a todo advenimiento discursivo.

La celebración es el espíritu que vivifica todo acto ritual, ceremonial de cualquier sistema religioso. Sin celebración, el rito carecería de valor, el gesto significativo carecería de validez y el símbolo se perdería en la nada.

La expresión significativa es una acción fundante de la celebración que hace parte de la relación y comunicación de los seres humanos, es una acción discursiva, pero que no se agota en lo puramente verbal, puesto que lo no verbal rebasa a través de su fuerza simbólica la palabra hablada, el gesto es en sí mismo un discurso preñado de símbolos, por esto es menester hablar de gesto-simbólico.

El mundo del lenguaje no es limitado pues se nutre de la vida misma, de la vida cotidiana para trasmitir sentimiento y estados intrínsecos que en momentos especiales se trasmiten a través de acciones simbólicas cargadas de sentido, develando el mundo interior por medio de la palabra y la gestualidad.

Ahora bien, para explicar de forma satisfactoria el tema de la expresión significativa al interior del concepto de fiesta sagrada (celebración), es necesario plantear una distinción acuciosa entre los conceptos de: señal, símbolo y gesto simbólico, entendidos como el vehículo o puente en el acto comunicativo. Esto es, los tres actúan como un medio al interior del proceso de la interacción comunicativa. Por señal entendemos todo lo evocado por el significante, es decir la palabra dicha que lleva en si una carga significativa, mientras que el gesto se ubica en el acervo de la comunicación no verbal, más aún, este trasciende cuando deja 
de ser mero gesto para transformarse en gesto simbólico; esto es, en una acción gestual y simbólica cargada de contenido vivencial.

La señal es el significante que se da en el proceso de significación, por ejemplo el humo que sale de una montaña es la señal que transmite un acontecimiento: un incendio, una llamada de auxilio, etc.; la señal es el significante porque manifiesta una información inmediata y este evoca un conocimiento que a su vez está referido al conjunto de significados posibles. Esto quiere decir que la señal es el primer estímulo en el proceso de percepción de la significación, ya la interpretación de la señal hace parte del universo del mundo del signo.

De otro lado, el gesto es una acción motora cargada de significado emotivo, afectivo y sentimental. Esto quiere decir que el gesto hace parte del arsenal del lenguaje no verbal. Es un modo de comunicarse, de entenderse con el otro. De ahí que el 80 \% de la comunicación es gestual, y tan solo un 20 \% pasa por la producción de discursos prosódicos.

El gesto simbólico es un gesto cargado de una intencionalidad comunicativa producido y aceptado convencionalmente, por ejemplo la elevación de la ostia en el símbolo eucarístico. El gesto simbólico representa la acción social instituida y legitimada por una tradición eclesial que comprende el gesto.

El gesto simbólico, así visto, es una acción cultural o individual con la finalidad de contribuir al proceso de comunicación entre un alter y un ego, pero desde la perspectiva de un intercambio mutuo de vivencias significativas. Por ejemplo, en la celebración de la eucaristía lo que comunica el Padre es una serie de vivencias y tradiciones que actúan como mecanismo de intercepción entre él y los fieles, y que está acompañado de gestos significativos que generan y producen emoción, afectos, sentimientos de amor, unión etc.

El gesto simbólico, desde esta perspectiva, se convierte en la memoria de prácticas realizadas por los ancestros, su contenido está cargado de tristezas, pasiones, esperanzas y sueños, de esta manera el gesto adquiere sentido, lo simbólico trasciende en el tiempo delegando a las nuevas generaciones, significados que van más allá de la simple cotidianidad mecánica. El gesto simbólico se convierte para muchas comunidades en un símbolo de identidad y belleza que representa las costumbres y tradiciones de un pueblo, que se asumen como una herencia valiosa que merece la conservación. Por esta razón, dentro del ámbito de lo eclesial, el gesto simbólico es también la manifestación del sentir de un pueblo, la comunidad de creyentes que se comunican no solo a través de actos verbales, sino también, y más importante aún, a través de gestos simbólicos que describen la realidad experiencial y vivencial de estos en comunión.

El gesto simbólico hace parte del acervo de expresiones significativas de las acciones rituales de la celebración de fe, o fiesta sagrada. Esta a su vez, también es un gesto simbólico, en sí misma, porque representa el momento significativo de encuentro trascendental entre los miembros de una comunidad de creyentes. 
Ella es un gesto, ella significa algo en el imaginario colectivo de quienes acuden a su vivencia. Pero esta al mismo tiempo encierra otra serie de gestos simbólicos de todo tipo: ornamentales, alimenticios, sacramentales, etc.; todo con el fin de hacer de esta una celebración significativa, una vivencia colectiva sagrada, un gesto simbólico de fe.

La celebración es la fiesta de un colectivo de personas pertenecientes a una cultura determinada, que a través de la manifestación gestual y simbólica representan festivamente el hecho ritual como un medio de sacar por medio de la fuerza interior las debilidades y fortalezas como símbolo de trascendencia, para morir y nacer como seres limpios y llenos de una nueva vida. La celebración es alegría y renovación, es crecimiento individual y colectivo, es el encuentro con una nueva vida llena de esperanza.

Ahora bien, si la comunicación es el medio de transmisión de la información en dos niveles: el verbal y no verbal, esto significa que la celebración es una acción o expresión significativa cargada de sentido, vivencias y afectos que debe ser transmitida por medio de un discurso, puesto que, aunque ella misma es gesto simbólico su comunicación postrera, esto es, para las próximas generaciones, debe hacerse desde un tipo específico de discurso. De hecho en los orígenes de la constitución del pueblo de Dios (vease el libro de los Hechos de los apóstoles), la celebración se comunica a través de las experiencias de vida, pero debía ser también contada para aquellas generaciones más lejanas. Es desde esta perspectiva que el tipo de discurso en el que se enmarca el símbolo como gesto significante, como lenguaje no verbal, y que hace parte de la acción de la celebración, es un discurso narrativo. Pues este es siempre evocativo, anecdótico, experiencial, vivencial. La narración como género literario no comunica formulas ni resultados sino expresiones de vida, y en ese sentido es la forma propia del quehacer de la celebración ceremonial, de la fiesta sagrada. De ahí que la narración sea el medio más eficaz de trasmisión del saber ancestral para un sin número de comunidades indígenas.

Por lo anterior, todo hecho religioso se enmarca dentro del ámbito de la celebración, de la fiesta ceremonial, la acción simbólica significativa, que no solo expresa un tipo específico de discurso, sino que antes bien, manifiesta de forma directa a través de un gesto simbólico toda su fuerza persuasiva. Esto es, la experiencia colectiva de un pueblo. No obstante, la celebración como signo, gesto simbólico y acción ritual renovada debe ser contada, y para ello la narración es el mejor mecanismo de comunicación, puesto que la narración no dice, evoca, expresa transmite sensaciones y afectos.

\section{Aspecto filosófico}

Es precisamente ese acto de celebración, de unión con el otro, y lo otro (divinidad) lo que deviene en la muerte del juicio crítico. Pues, es el otro divino, sagrado 
el que salva, instituye y constituye la realidad material y espiritual de aquel. El yo auténtico se pierde en el otro superfluo, etéreo, metafísico, ajeno. Es a través del otro que la propia vida adquiere valor. La propia vida carece de toda positividad porque, de ante mano, la subjetividad discursiva producida por tal cosmovisión, instituye en el imaginario colectivo del fiel, seguidor o devoto la idea de que él es una nada mientras que la divinidad es algo, a tal punto que mientras más se aleje de la voluntad de esta más nada será. Nada que se traduce en sujeto de pecado, de ataduras, de deseos, pues su cuerpo es lastre para el alma y su sexualidad corrección para el espíritu: acto fundante de procrear sin pasión sexual o erótica formativa. El terrible resultado: un individuo atrapado en patologías sexuales de la conducta, un yo pecador frente a un yo deseante desbordan en un yo enfermo sexual.

La salvación jamás está en el sujeto de deseo, está por fuera de él. Por eso la malignidad de unirse con el ser de no deseo (la divinidad). Lo curioso es que todos los mitos antiguos confirman lo mismo: los dioses bajan a la tierra a tener relaciones sexuales con las mujeres de los hombres. Y entonces, ¿no es esta una perspectiva hipócrita del deseo, de la unión de la celebración?, ¿no es esta, acaso, la peor de las mentiras en contra de la vida sexual de los hombres? Desde la perspectiva eclesial, el hombre no piensa, reproduce fielmente los discursos del sacerdote, pastor o guía espiritual, pero paradójicamente, los reproduce siempre en oposición a sus acciones cotidianas manifiestas en su mundo subjetivo-privado. Y los sacerdotes, pastores y gurús saben bien de eso: acoso sexual a seminaristas, adeptos y seguidores; abuso del poder y cercenación del pensamiento crítico. La capacidad de pensar la serpiente bíblica, que realmente representaba el conocimiento verdadero en el mundo antiguo, ha desaparecido por completo ante el influjo maligno y perverso del otro (dios, la tribu) que salva lo que la propia naturaleza no puede salvar. Los escritos sagrados piensan por el fiel. El acto de unión a través del ritual de celebración lo ponen en sintonía con la comunidad de creyentes, lo hacen ajeno a sí mismo (alienación ideológica) atrapado en una lógica de la histeria colectiva; la promesa de salvación, de un mundo mejor en el más allá, lo sacan de su realidad cultural, política y existencial, reducen su vida a la creencia en un más allá carente de todo más acá. Tal acción social hace de la vida un acto sin sentido natural y de la muerte un acto trágico de culpa.

Así pues, en la experiencia cultural al interior de distintos cultos religiosos se ha podido evidenciar que en los miembros pertenecientes a tal fenómeno social existe una pérdida del juicio crítico, debido a la imposición dogmática de preceptos, reglas, prácticas y leyes que la institución religiosa instituye como practica de vida ante sus fieles, de modo que el ejercicio reflexivo o el atrevimiento de cuestionar el libro sagrado pasa a ser un acto de infidelidad, arrogancia y pérdida de fe, sobre el patrón de comportamiento definido de antemano por la jerarquía eclesial. Instituyendo desde luego, una subjetividad discursiva bien específica (religiosa), esto es, siempre excluyente y auto-comprensiva; lo que quiere decir que solo su cosmovisión posee fuerza persuasiva, es verdad, es legítima; al mismo tiempo que promueven un sinnúmero de patologías de 
la conducta castrando en sus fieles, o seguidores, la posibilidad de conocer otras cosmovisiones, formas de ser, de obrar o de concebir la realidad, que permitan la superación del hombre de hoy, el homo-consumidor. De modo tal que transforman a sus seguidores y adeptos en seres manipulados, impedidos, castrados, circuncidados doctrinalmente; a tal punto que se les impide ser ellos mismos, ser dueños de su propio destino. En contraposición a esto surge el pensamiento filosófico, de unos pocos, no profesionales del saber, ni eruditos de la verdad, como vía de escape que permite observar con más lucidez el fenómeno en cuestión.

Si bien a lo largo de la historia, que se ha podido rastrear, se ve inmerso el fenómeno religioso en lógicas de poder, el pensamiento filosófico fluctúa alrededor de este acontecer como acto de revisión constante, de modo preponderante en cada momento de furor o supuesta pasividad de la historia, determinando el papel ideológico, existencial o fenoménico del hecho religioso. Tanto así que primero en la reforma, luego en el romanticismo, posteriormente en la revolución francesa, y finalmente en la segunda guerra mundial, se avecinó un pensamiento crítico que señalaría los males que se habían cultivado en la humanidad, cuyo resultado más brillante será el genio de Nietzsche en el siglo XIX y posteriormente el de Foucault en el XX.

Gracias al poder que los emporios religiosos y los imperios económicos adquirían con el ánimo de someter al pueblo, especialmente la religión más difundida en el mundo occidental, el cristianismo, un judaísmo por extensión en todo caso, que con su ideología del pecado se propuso expandirse por toda la faz de la tierra a toda costa, sometieron a las cosmovisiones tradicionales de los pueblos del tercer mundo y a las ideologías materialistas de la historia, a un proceso de exclusión social, marginación política y desconocimiento social. La educación ha sido su arma más poderosa, y el comercio su didáctica más eficaz. Su propuesta evangelizadora comprendida como promesa de salvación habría de aglomerar a cuantos fuera posible, pero: los sufridos, los desconsolados, los débiles que cada vez eran más, se convirtieron en el objetivo primordial de los líderes de dicha religión, constriñendo el mundo de la vida de sus seguidores a un solo horizonte de sentido: su aceptación social, política y existencial como pobres; a tal punto que aquellos llegaron a enfermar y se transformaron en profesionales, trabajadores y obreros agradecidos. Tal supuesta cura fue entonces aun más agobiante para el hombre, ya que para alcanzar la dicha de la otra vida debe restringirse en esta toda felicidad posible: lo que hace al ser humano precisamente humano, el pathos, todo acto de emancipación real, toda genialidad posible. Genocidio de todo aquello que hace al hombre fuerte, vital, pleno (Nietzsche, 2000); en otras palabras, aquellos debían negar tal naturaleza para masacrar sus instintos primarios que les permiten la exudación de la vida para que se repriman hasta enfermar.

El hombre desde la incursión comercial semítica, de la revolución industrial (1780 d. C.), ha soñado con la emancipación, pero son pocos los que poseen el valor de guiar la voluntad hacia ella. En consecuencia de esa falta de arrojo 
surgen las multitudes temerosas, las tribus urbanas: los débiles de mente, escasos de ánimo, cortos en creación, y se imponen los fáciles de someter, ovejas que solo pueden vivir encorraladas y manipuladas por el pastor, animales domesticados que han vendido su libertad a cambio de una certeza inexpugnable, la certeza en otra vida plena, eterna e inmutable, la comprensión mecánico-racional del fenómeno de la muerte y la emulación creciente de una vida sin sentido. Así pues, lo que queda rebajado a la categoría nihilista es la vida misma. El hombre de hoy: una máquina de consumo y deseo de hiper-realidad ciber-espacial.

De ahí que, el sentido de una vida auténtica se impone como meta a lograr para los que creen en una filosofía por una vida plena, en la que se opta por la salvación, no espiritual, sino psico-somática y socio-afectiva del hombre en su aquí y en su ahora. La vida como plenitud en oposición a la vida como acción pasiva del pecado, es la propuesta de una filosofía por y para la vida, una vida heroica dirigida por la acción formativa, no de la narrativa ceremonial, sino por la acción ardua y constante de la acción pedagógica sobre el propio cuerpo en sus múltiples dimensiones. El resultado, un hombre y una mujer plenos hechos a punta de martillo y cincel.

En conclusión, el hecho religioso deviene en la vida del hombre como una respuesta a su propia tragedia, la tragedia del existir sin la conciencia del por qué y para qué se existe. La biológica aparece en este como un obstáculo a ser superado, el otro acontece como un hecho trágico, pero al mismo tiempo paradójico, ya que solo a través del otro el hombre puede superar su minusvalía orgánica, pero a costa de la creación de una prótesis artificial, la cultura, un mundo de la vida por descifrar. En este sin sentido de la existencia, la creencia artificial, simbólica y creativa de un mundo mejor, de un más allá eterno e inmutable, que no puede ser rebajado por el hecho factico de la muerte, es cuando surge el acontecimiento del fenómeno religioso como la posibilidad de un mundo cualitativamente mejor, en donde el sufrimiento del drama trágico de la vida deviene como un capítulo de la existencia que no debe ser recordado, como esa etapa de la animalidad del hombre superada por el ser espiritual de la trascendencia. Es así como el hombre descubre el sentido de su propia existencia. 


\section{$\mathbf{R}_{\text {eferencias }}$}

Bolk, L. (1926). Teoría de la retardación. Cali: Universidad del Valle.

Durkheim, E. (1982). Las formas elementales de la vida religiosa. Madrid: Alianza.

Foucault, M. (1994). Estética, ética y hermenéutica. Barcelona: Paidós.

Geheln, A. (1993). Antropología filosófica. Barcelona: Paidós.

Marquart, O. (2001). Teoría de la compensación. Barcelona: Paidós.

Nietzsche, F. (2000a). El anticristo. Barcelona: Gedisa.

Nietzsche, F. (2000b). Sobre el porvenir de nuestras instituciones educativas. Barcelona: Tusquets.

Taborda, F. (1987). Sacramentos, praxis y fiesta. Madrid: Paulinas.

Weber, M. (1999). Sociología de la Religión. Madrid: Porrúa. 